\title{
Dependence of blood indices of selenium and mercury on estimated fish intake in a national survey of British adults
}

\author{
Christopher J Bates ${ }^{1, *}$, Ann Prentice ${ }^{1}$, Maureen C Birch ${ }^{1}$ and H Trevor Delves ${ }^{2}$ \\ ${ }^{1}$ MRC Human Nutrition Research, Elsie Widdowson Laboratory, Fulbourn Road, Cambridge CB1 9NL, \\ UK: ${ }^{2}$ SAS Trace Element Unit, Chemical Pathology, Southampton General Hospital, Southampton, UK
}

Submitted 22 November 2005: Accepted 20 April 2006

\begin{abstract}
Objective: Contributions of fish and other foods to variance of selenium and mercury status were studied in British adults.

Setting and design: Plasma and red-cell selenium and whole-blood mercury concentrations were measured during the National Diet and Nutrition Survey of Adults aged 19-64 years in mainland Britain, 2000-2001 $(n=1216)$. Food intake was weighed for seven consecutive days, and foods were combined in groups for data analysis. Four subsidiary groups characterised fish intakes: fried white fish, 'other' white fish, shellfish and oily fish.

Results: Geometric means and 5-95\% ranges were: for whole-blood mercury, 5.61 (1.30-22.2) $\mathrm{nmoll}^{-1}$; for plasma selenium, $1.09(0.83-1.43) \mu \mathrm{moll}^{-1}$; for red-cell selenium, $1.64(1.14-2.40) \mu \mathrm{moll}^{-1}$. Twenty-eight per cent had no fish intake recorded during 7 days; the remaining $72 \%$ had a median intake of $237 \mathrm{~g}$ over the 7-day period, 5-95\% range 45-780 g. Total fish intake was strongly and directly correlated with blood mercury, and moderately with red-cell and plasma selenium. Thus, sqrt(total fish intake) was correlated with: $\log _{\mathrm{e}}$ (blood $\mathrm{Hg}$ ), $t=+19.7$; $\log _{\mathrm{e}}\left(\right.$ plasma Se), $t=+9.8$; and $\log _{\mathrm{e}}($ red-cell Se), $t=+9.6$, all $P<0.0001$. All three biochemical (mercury and selenium) indices were strongly correlated with oily fish intake, and moderately correlated with shellfish and 'other' ( $=$ non-fried) white fish, but none was significantly correlated with fried white fish. Blood mercury was strongly and directly correlated with red-cell and plasma selenium, and both increased with age.

Conclusions: Dietary fish, especially oily fish, is a strong predictor of blood mercury and selenium in British adults.
\end{abstract}

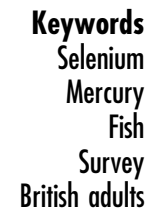

Dietary fish provide a rich source of the essential element selenium ${ }^{1}$. Dietary selenium sources have declined recently in the UK, accompanying declining grain imports from selenium-rich North America ${ }^{2}$. Fish, especially oily fish, provide essential $n-3$ fatty acids and other valuable nutrients. However, they also concentrate some potentially toxic substances, especially those that readily cross membranes. One is mercury, converted from inorganic forms to methylmercury chloride by marine bacteria ${ }^{3-5}$. Inorganic mercury may be present in the human body in the form of mercury amalgam fillings in teeth, and small quantities of this mercury may be released into the circulation (mainly into the plasma). Mercury has no known beneficial functions in the human body, but at toxic levels can cause long-term damage to the developing (foetal) brain, after crossing the placental and blood-brain barriers, and can cause congenital malformations, kidney damage and immune system malfunction ${ }^{6}$.

Fish contribute, on average, about one-third of the British population's total dietary intake of mercury, which amounts to about $3 \mu \mathrm{g}$ daily for an average British adult ${ }^{7}$. Most of the mercury in fish occurs as methylmercury cysteine $^{8}$, which may be converted to methylmercury chloride in the human stomach and then back to the cysteine-bound form in tissues such as red cells, into which it is transferred and concentrated from the plasma and where it becomes bound to the cysteine side-chains of haemoglobin. Most of the mercury in blood ( 95\%) is located within the red cells and is derived from the organic forms of mercury that predominate in food. In contrast, selenium is distributed about 60\%:40\% between the red cells and the plasma, and is present both in selenoproteins with genetically encoded selenium and in selenomethionine which is coded by the methionine codon, and thus randomly replaces methionine in all proteins. Haemoglobin contains a major proportion of red-cell selenium, which is mainly in the form of bound selenomethionine?

Selenium and mercury have long been known to interact chemically with each other in various ways, both in vitro and within the body, and many studies during 
the past three or four decades have reported a strong direct relationship between the biochemical indices of mercury accumulation and those of selenium status within the human (and animal) body ${ }^{10,11}$. However, the significance of this interaction for the detoxification and removal of mercury from the body is not well understood $^{12}$, and it probably involves a number of different processes. When entering the body mainly from food sources such as fish (rather than from inorganic sources such as industrial mercury exposure or dental amalgam), most of the mercury that enters and remains in the bloodstream is in the red cells, where it binds to haemoglobin as a methylmercury-cysteine side-chain complex $^{4,8}$. The interaction of organic forms of mercury with selenium and its compounds is less well understood than the interaction that occurs between inorganic mercury and selenium, and requires further study.

In 2000-2001, the National Diet and Nutrition Survey (NDNS) of people aged 19-64 years was performed in mainland Britain. It represented the adult age group (exclusive of pregnant and breast-feeding women) in a rolling series of national surveys that spanned age ranges from 1.5 years to $85+$ years. The respondents who were invited to participate in each NDNS were selected to be, as far as possible, representative of the British population. The procedures in the adults' survey included a sevenconsecutive-day weighed food intake record and a nonfasting blood sample for a range of biochemical status analyses, including selenium and mercury. The survey objectives and methods, and main outcomes, are described in five survey reports published by The Stationery Office $^{13-17}$. The estimated mean consumption of white fish by British adults from the NDNS ${ }^{13}$ was $103 \mathrm{~g}^{\text {week }}{ }^{-1}$, and of oily fish, $50 \mathrm{~g}$ week $^{-1}$. For fish consumers, the mean values were 221 and $194 \mathrm{gweek}^{-1}$, respectively. The purpose of the present study was to examine the relationships between estimated food intakes and mercury and selenium indices in the survey participants, to test the hypothesis that fish intakes are major contributors to these elements, in a population that includes women of childbearing age.

\section{Methods}

The main survey procedures are described in the published survey reports ${ }^{13-17}$, so only a brief summary is included here. The population sample was obtained by random selection of eligible individuals living in 152 randomly chosen postcode sectors, which were randomly allocated to four sequential 3-month 'rounds' of fieldwork, beginning in July 2000. Participation was invited but not compulsory and partial participation was possible. The survey included a demographic/socio-economic/lifestyle questionnaire, a weighed dietary record kept for seven consecutive days, and a non-fasting blood sample taken by a trained phlebotomist in the participants' home. Three sub-samples of blood were distributed and used for a wide range of biochemical status measurements. For trace element analysis, containers containing ethylenediamine$N, N, N^{\prime}, N^{\prime}$-tetraacetic acid (EDTA) were used. Permission was given for the survey procedures by a Multi-centre Research Ethics Committee and by individual National Health Service Local Research Ethics Committees representing each of the participating postcode sectors.

Trained interviewers assisted the respondents to keep weighed records of intakes of all foods eaten at home, plus diary records of foods eaten outside the home, for seven consecutive days. These records included dietary supplements, information about brands of manufactured foods, methods of food preparation, and leftovers. Computer and face-to-face checks for completeness and consistency were performed. The interviewers allocated the food items to about 6000 food codes, each code being allocated to one of 106 subsidiary food groups, which were in turn aggregated into 57 main food groups and then into 11 major food types. For the present study, the 106 subsidiary food groups provided the basis for analysis of food choices. There were four categories of fish intake within the 106 subsidiary food groups: fried white fish, other white fish, shellfish, and oily fish. We refer to the sum of these four categories as total fish intake.

All three blood indices that are considered in the present study (i.e. concentrations of whole-blood Hg, plasma Se and red-cell Se) were measured in the SAS Trace Element Unit of the University of Southampton at Southampton General Hospital. The EDTA-stabilised blood samples were sent by first-class post to the analytical laboratory, where part of each sample was centrifuged to yield plasma, and this, together with the residue of whole blood, was stored frozen.

For the selenium assays, $100 \mu \mathrm{l}$ samples of blood plasma and of whole blood were each diluted with 14 volumes of an aqueous solution containing $1 \% \mathrm{v} / \mathrm{v}$ butan-1-ol, $0.66 \%$ $\mathrm{v} / \mathrm{v}$ Triton $\mathrm{X}-100,0.01 \mathrm{M}$ ammonium hydroxide, $0.2 \mathrm{mM}$ diammonium dihydrogen EDTA and $2 \mathrm{mM}$ ammonium dihydrogen phosphate ${ }^{18} .{ }^{78} \mathrm{Se}$, the second major natural isotope of selenium (23.8\% natural abundance), was quantified by inductively coupled plasma-mass spectrometry (ICP-MS). The choice of diluent ensured negligible interference from argon adducts. Matrixmatched bovine serum containing selenium standards were used for calibration. In the assays of plasma selenium, internal quality control (ICQ) was achieved by using bovine sera with Se added at $0,0.4$ and $1.6 \mu \mathrm{M}$. Nycomed Seronorm quality control samples with assigned values were used for accuracy verification. Participation in UK TEQAS (Trace Element Quality Assurance Scheme, University of Surrey) and a quality assurance scheme organised by the Centre du Toxicologie de Quebec provided inter-laboratory comparisons. The overall mean coefficient of variance for five different IQC samples, which were included after every tenth duplicate unknown 
sample, was 5.3\%, and assay drift over the 3-month analysis period was $<1.3 \%$. The mean bias between observed and target concentrations for the five ICQ samples was $+0.03 \mu \mathrm{moll}^{-1}\left(+2.0 \mu \mathrm{g} \mathrm{l} \mathrm{l}^{-1}\right.$ or $\left.+2.9 \%\right)$. The performances in both of the above external quality assurance (EQA) schemes at the time of analysis of the survey samples were excellent, with $85 \%$ and 100\% of results within inner and outer target limits about median values for all participating laboratories - an acceptable performance is $60 \%$ and $80 \%$ within these limits. In 2001 there was no Quebec EQA scheme for Se in whole blood, however there was a multi element scheme then being set up, called 'ICP MS Comparison Scheme'. It is now known as 'Quebec multi-element EQA scheme' in which one of the elements was selenium. We participated in this scheme, and this was the source of the 17 EQA results for blood Se in the paragraph after next. IQC was achieved using two samples of whole bovine blood and three certified reference samples of whole blood (Nycomed ref. 404107, 404108 and MR9067). The mean bias between observed and target concentrations for these certified reference materials was $+0.02 \mu \mathrm{moll}^{-1}\left(+1.7 \mu \mathrm{gl}^{-1}\right.$ or $1.7 \%$ ). Red-cell selenium concentrations were calculated from whole-blood and plasma selenium concentrations, together with the haematocrit.

Whole-blood mercury concentrations were measured in the same laboratory and by a similar method ${ }^{19}$. Blood samples $(100 \mu \mathrm{l})$ were diluted with 14 volumes of an aqueous solution of $0.7 \%$ Triton $\mathrm{X}-100,0.12 \mathrm{M}$ ammonium hydroxide, $0.0005 \mathrm{M}$ diammonium dihydrogen EDTA and $0.005 \mathrm{M}$ ammonium dihydrogen phosphate. Calibration was achieved using matrix-matched standards containing mercury added to bovine blood. IQC was achieved by using laboratory-prepared pools of bovine blood with added mercury. A large sample of bovine blood (containing $\mathrm{Hg}$ at $0.1 \mu \mathrm{gl}^{-1}$ or $\sim 5 \mathrm{nmoll}^{-1}$ ) was spiked with $\mathrm{Hg}$ at three levels. 2.5, 5.0 and $10.0 \mu \mathrm{gl}^{-1}$ (equivalent to $\sim 12.5,25.0$ and 50.0 nmol $\mathrm{Hgl}^{-1}$ ) to give a total of four pools of IQC blood samples. In addition, accuracy verification was achieved using commercially available Nycomed quality control samples with assigned values to control assays for wholeblood mercury. A set of at least two IQC and/or reference samples was analysed at a frequency of not less than one set per 10 duplicate survey samples. Participation in the EQA scheme organised by the Centre du Toxicologie de Quebec for whole-blood mercury provided inter-laboratory comparisons/external assessment of accuracy of analyses.

The mean biases, i.e. the differences between the mean of the Southampton results and the mean of the target values for samples from the EQA schemes, were as follows: UK TEQAS for serum Se, $-0.05 \mu \mathrm{moll}^{-1}$ at $1.56 \mu \mathrm{moll}^{-1}$ $(-3.0 \%, \quad n=36)$; Quebec EQA for serum Se, $-0.11 \mu \mathrm{moll}^{-1}$ at $2.08 \mu \mathrm{moll}{ }^{-1}(-5.4 \%, n=27)$; Quebec EQA for whole-blood Se, $-0.18 \mu \mathrm{moll}^{-1}$ at $2.84 \mu \mathrm{mol} \mathrm{l}^{-1}$ $(-6.4 \%, n=17)$; and Quebec EQA for whole-blood $\mathrm{Hg}$, $+0.56 \mathrm{nmoll}^{-1}$ at $79.6 \mathrm{nmoll}^{-1}(+0.70 \%, n=18)$. These performances were assessed as being 'excellent' for serum Se in UK TEQAS and for whole-blood $\mathrm{Hg}$ in the Quebec EQA schemes, and 'good' for Se in both serum and blood in the Quebec EQA schemes. The much higher selenium concentrations in serum and blood samples from Quebec EQA reflect the higher concentrations seen in the Canadian population; they were greater than those seen in the UK population and in the EQA samples from UK TEQAS, and were above the usual calibration range.

\section{Statistical methods}

Statistical analyses were performed using the DataDesk (Data Descriptions Inc.) statistical programme, and included both univariate and multivariate linear regression. In the survey reports, weighting factor adjustments have been used to correct for the known sociodemographic differences between the composition of the survey sample and the entire (census) population of Great Britain, but these were considered unnecessary for the present study, which mainly considers the crosssectional comparisons between different indices.

A summary distribution of the blood index values is provided in the fourth survey report ${ }^{16}$. All three indices exhibited a positively skewed distribution, and the distribution for mercury was more strongly skewed than the two selenium indices. After $\log _{\mathrm{e}}$-transformation, all three indices had a normal (Gaussian) distribution as indicated by skewness estimates between -1.0 and +1.0 . Therefore, all data comparisons for the present study were performed with $\log _{\mathrm{e}}$-transformed biochemical index values.

The analytical approach to the relationships between the blood indices and the food group intakes was tailored to be compatible with the large number of zero intakes in the 7-day diet records for many of the subsidiary food groups that were of interest. For the intake-status comparisons shown in Tables $1-3$, the intake (in $\mathrm{g} / 7$ days) of each individual food group was scored as ' 1 ' for a zero recorded intake during the 7-day period, and as '2', ' 3 ' or ' 4 ' for ascending thirds of non-zero intake, these scores being entered into linear regression analysis versus the natural logarithm of the blood indices. For the analysis in Table 4, the square root of the 7-day food group intake for fish groups and non-fish groups was entered into linear regression versus the logarithm of the blood indices (all intake estimates were either 0 or $\geq 1.0$ ). Square-root transformation of the numerical values of the food group intakes was used to reduce any disproportionate contributions to the regressions by high outliers. Square-root transformation was used (1) because many of the estimated intake values were zero, which is incompatible with logarithmic transformation, and (2) there were no values below 1.0; therefore square-root transformation reduced the positive skewness in these datasets. Subdivision of food group intakes into four ascending categories and squareroot transformation both yielded similar conclusions with respect to the food intake-blood index relationships. 
Table 1 Blood mercury concentrations by defined ranges of fish intake

\begin{tabular}{|c|c|c|c|c|c|}
\hline $\begin{array}{l}\text { Categories } \\
\text { and scores } \\
\text { for fish intake }\end{array}$ & $\begin{array}{l}\text { Range of intakes } \\
\text { (g/7 days) }\end{array}$ & $\begin{array}{l}\text { Median } \\
\text { intake } \\
\text { (g/7 days) }\end{array}$ & $n$ & $\begin{array}{l}\text { Geometric mean } \\
\text { blood } \mathrm{Hg}\left(\mathrm{nmoll}^{-1}\right)\end{array}$ & $\begin{array}{l}t \text { for linear } \\
\text { regression }\end{array}$ \\
\hline \multicolumn{6}{|l|}{ Fried white fish } \\
\hline 1 & 0 & 0 & 800 & 5.44 & 1.8 \\
\hline 2 & $0.1-125.0$ & 102 & 145 & 5.14 & \\
\hline 3 & $125.1-180.0$ & 170 & 131 & 6.53 & \\
\hline 4 & $>180.0$ & 251 & 140 & 6.01 & \\
\hline \multicolumn{6}{|c|}{ Other white fish } \\
\hline 1 & 0 & 0 & 1000 & 5.05 & $7.7^{\star \star \star}$ \\
\hline 2 & $0.1-133.0$ & 90 & 71 & 9.71 & \\
\hline 3 & $133.0-248.0$ & 170 & 72 & 7.34 & \\
\hline 4 & $>248.0$ & 340 & 73 & 9.66 & \\
\hline \multicolumn{6}{|l|}{ Shellfish } \\
\hline 1 & 0 & 0 & 988 & 5.02 & $9.3^{\star \star *}$ \\
\hline 2 & $0.1-49.0$ & 30 & 75 & 7.36 & \\
\hline 3 & $49.1-124.0$ & 75 & 77 & 8.67 & \\
\hline 4 & $>124.0$ & 256 & 76 & 10.73 & \\
\hline \multicolumn{6}{|l|}{ Oily fish } \\
\hline 1 & 0 & 0 & 665 & 3.79 & $19.2^{\star \star \star}$ \\
\hline 2 & $0.1-100.0$ & 59.5 & 194 & 6.99 & \\
\hline 3 & $100.1-201.0$ & 140 & 176 & 9.05 & \\
\hline 4 & $>201.0$ & 318 & 181 & 11.40 & \\
\hline \multicolumn{6}{|c|}{ All fish combined } \\
\hline 1 & 0 & 0 & 344 & 2.97 & $18.5^{\star \star *}$ \\
\hline 2 & $0.1-170.0$ & 100 & 284 & 5.49 & \\
\hline 3 & $170.1-335.0$ & 235 & 300 & 6.80 & \\
\hline 4 & $>335.0$ & 475.5 & 288 & 9.76 & \\
\hline
\end{tabular}

From the entire survey dataset of food group intakes, each category of fish intake (i.e. fried white fish, other white fish, shellfish, oily fish) was subdivided into zero recorded intake and three ascending thirds of intake, so as to generate a score of 1 to 4 for each food group. The cut-off values for thirds of intakes were calculated from all survey respondents who provided intake data, but only about $73 \%$ of these had blood measurements. Although canned tuna may be considered relatively non-oily, it is included in the category 'oily fish' because whole tuna is classified as an oily fish. The linear regressions relate the $\log _{e}($ blood $\mathrm{Hg}$ ) values to the fish intake scores for each category of fish, and are adjusted for age and gender.

${ }^{\star \star \star} P<0.0001$; otherwise not significant $(P>0.05)$

$P<0.05$ is used as the cut-off for significant differences except in Table 4, where large numbers of food groups are being compared. Here, food groups are included in the table only if at least one of the three comparisons with the blood indices is significant at $P<0.005$.

\section{Results}

Response rates for participation in each main part of the survey were as follows. From an eligible sample of 3704 individuals, $2 \%$ could not be contacted and $37 \%$ refused to participate. The dietary interview was thus completed by 2251 (61\% of the eligible sample) and the 7-day weighed dietary record was completed by 1724 ( $47 \%$ of the eligible sample). A blood sample was obtained from 1318 subjects (36\% of the eligible sample), and measurement of the mercury index plus the two selenium indices was achieved for 1216 subjects (33\% of the eligible sample).

In this British adult population sample, the unweighted median values for blood $\mathrm{Hg}$ concentration in men increased from $2.3 \mathrm{nmoll}^{-1}$ in the age group 19-24 years to $6.3 \mathrm{nmoll}^{-1}$ in the age group 50-64 years, and for women the unweighted median values increased from $4.3 \mathrm{nmoll}^{-1}$ in $19-24$-year-olds to $6.6 \mathrm{nmoll}^{-1}$ in the $50-$ 64 -year-olds ${ }^{16}$. The highest observed value was
$133 \mathrm{nmoll}^{-1}$ and $129 / 1216$ (10.6\%) of values were $>15 \mathrm{nmoll}^{-1}$, which has been used as a cut-off below which most non-occupationally exposed subjects should fall $^{20}$; however no values $>250 \mathrm{nmoll}^{-1}$, the limit of toxicity, were found. The unweighted median red-cell Se concentration in men varied between 1.40 and $1.59 \mathrm{moll}^{-1}$, and in different age groups of women it varied between 1.68 and $1.76 \mu \mathrm{moll}^{-1}$. The unweighted median plasma Se concentration varied between 1.04 and $1.11 \mu \mathrm{moll}^{-1}$ in the different age-gender groups ${ }^{16}$. Both blood $\mathrm{Hg}$ and plasma Se (and to a lesser degree, red-cell Se) varied significantly between social class categories, with the lowest values of all three indices in the manual and unskilled categories. For instance, the geometric mean blood $\mathrm{Hg}$ concentration $\left(\mathrm{nmol}^{-1}\right.$ ) was 8.3 in social class 1, 7.3 in class 2, 5.4 in class 3.1, 4.8 in class 3.2, 4.2 in class 4 and 3.7 in class 5. Likewise, plasma Se exhibited a regularly decreasing pattern from $1.21 \mu \mathrm{moll}^{-1}$ in class 1 to $1.01 \mu \mathrm{mol} \mathrm{l}^{-1}$ in class 5 .

From the data of the present study, it is clear that wholeblood Hg concentration (Table 1), red-cell Se concentration (Table 2) and plasma Se concentration (Table 2) all exhibited similar patterns of relationship with dietary fish intake. All three indices were significantly and directly correlated with intake of non-fried white fish, shellfish and 
Table 2 Red-cell and plasma selenium concentrations by defined ranges of fish intake

\begin{tabular}{lcccc}
\hline $\begin{array}{l}\text { Categories } \\
\text { and scores } \\
\text { for fish intake }\end{array}$ & $\begin{array}{c}\text { Mean } \\
\text { red-cell Se } \\
\left(\mu \mathrm{moll}^{-1}\right)\end{array}$ & $\begin{array}{c}t \text { for linear } \\
\text { regression }\end{array}$ & $\begin{array}{c}\text { Mean } \\
\text { plasma Se } \\
\left.(\mu \mathrm{moll})^{-1}\right)\end{array}$ & $\begin{array}{c}t \text { for linear } \\
\text { regression }\end{array}$ \\
\hline $\begin{array}{l}\text { Fried white fish } \\
1\end{array}$ & 1.65 & -1.3 & 1.100 & -1.4 \\
2 & 1.51 & & 1.069 & \\
3 & 1.66 & & 1.104 & \\
4 & 1.61 & & 1.074 & \\
Other white fish & & & & \\
1 & 1.60 & $5.2^{\star \star \star}$ & 1.079 & $4.5^{\star \star \star}$ \\
2 & 1.82 & & 1.196 & \\
3 & 1.70 & & 1.166 & \\
4 & 1.80 & & 1.127 & \\
Shellfish & & & & \\
1 & 1.60 & $5.9^{\star \star \star}$ & 1.079 & $5.7^{\star \star \star}$ \\
2 & 1.69 & & 1.114 & \\
3 & 1.80 & & 1.209 & \\
4 & 1.80 & & 1.149 & \\
Oily fish & & & & \\
1 & 1.54 & $11.2^{\star \star \star}$ & 1.049 & $10.8^{\star \star \star}$ \\
2 & 1.66 & & 1.103 & \\
3 & 1.77 & & 1.163 & \\
4 & 1.85 & & 1.190 & \\
All fish combined & & & & \\
1 & 1.54 & $8.2^{\star \star *}$ & 1.038 & $8.8^{\star \star \star}$ \\
2 & 1.58 & & 1.079 & \\
3 & 1.65 & & 1.106 & \\
4 & 1.79 & & 1.166 & \\
\hline
\end{tabular}

From the entire survey dataset of food group intakes, each category of fish intake (i.e. fried white fish, other white fish, shellfish, oily fish) was subdivided into zero recorded intake and three ascending thirds of intake, so as to generate a score of 1 to 4 for each food group. The range of fish intakes, the mean intakes and ' $n$ ' for each cell is the same as in Table 1. The linear regressions relate the mean red-cell or plasma selenium values to the fish intake scores, for each category of fish, and are adjusted for age and gender.

${ }^{\star \star \star} P<0.0001$; otherwise not significant $(P>0.05)$.

oily fish, and with all categories of fish combined, but were not significantly correlated with intake of fried white fish. The strongest correlation, for all three blood indices, was with oily fish intake. The magnitude of the $t$-values indicates that the correlation between the fish intakes and blood mercury concentration was stronger than between fish intake and either of the indices of selenium status.

Just as the biochemical status indices varied between social class categories, so did fish intake patterns. For instance, the sum of oily fish, shellfish and non-fried white fish was about four-fold greater in social class 1 than it was in social classes 4 and 5 combined.

The data in Table 3 confirm that there was a strong direct relationship between blood mercury concentration and each of the selenium indices, which was significant for all age-gender subgroups except the youngest group of women. The variation in the slope of a plot of $\log _{\mathrm{e}}$ (blood $\mathrm{Hg}$ concentration) versus $\log _{\mathrm{e}}$ (red-cell Se concentration) for all subjects combined suggests that the relationship was strongest at the higher concentrations of mercury (and selenium). Thus, the $t$-value for the slope corresponding to values of $\log _{\mathrm{e}}$ (blood $\mathrm{Hg}$ concentration) $>1.5 \mathrm{nmoll}^{-1}$ was 9.8, with $P<0.0001$, whereas the $t$-value for the slope corresponding to values of $\log _{e}$ (blood $\mathrm{Hg}$ concentration) $\leq 1.5 \mathrm{nmoll}^{-1}$ was $0.9, P=0.4$ (not significant).

Table 4 examines the relationships between the three biochemical indices and 7-day intakes of fish or other selected (non-fish) food group intakes, square-roottransformed. Eleven non-fish food groups were directly correlated with one or more of the biochemical indices and four were inversely correlated. The direction and significance of the relationships between the non-fish food groups and the three biochemical indices were essentially unaffected by including total fish intake in the regression model (not shown). The combination of age and sqrt(all fish) explained $27 \%$ of the variance of the mercury index; this was increased to $36.4 \%$ by the addition of 27 food groups (all sqrt intakes) which were significantly correlated (directly or inversely) with the mercury index. Some of these food group intakes were themselves

Table 3 Linear regression of $\log _{e}\left(\right.$ blood $\mathrm{Hg}$ ) against $\log _{\mathrm{e}}\left(\right.$ red-cell $\mathrm{Se}$ ) and against $\log _{\mathrm{e}}($ plasma Se), in respondents of the National Diet and Nutrition Survey, subdivided by gender and age group

\begin{tabular}{|c|c|c|c|c|c|c|c|c|}
\hline \multirow[b]{2}{*}{ Gender and age group } & \multicolumn{4}{|c|}{$\log _{e}\left(\right.$ blood Hg) vs. $\log _{e}($ red-cell Se) } & \multicolumn{4}{|c|}{$\log _{e}\left(\right.$ blood Hg) vs. $\log _{e}($ plasma Se) } \\
\hline & $\begin{array}{l}\text { Degrees } \\
\text { of freedom }\end{array}$ & Slope & SE (slope) & $t$ & $\begin{array}{l}\text { Degrees } \\
\text { of freedom }\end{array}$ & Slope & SE (slope) & $t$ \\
\hline \multicolumn{9}{|l|}{ Men } \\
\hline $19-24$ years & 37 & 0.066 & 0.023 & $2.8^{\star \star}$ & 38 & 0.057 & 0.016 & $3.5^{\star \star}$ \\
\hline $25-34$ years & 105 & 0.105 & 0.021 & 5.1 & 105 & 0.065 & 0.016 & $4.1^{\star \star *}$ \\
\hline $35-49$ years & 221 & 0.122 & 0.015 & $8.0^{\star \star \star}$ & 225 & 0.096 & 0.011 & $8.7^{\star \star \star}$ \\
\hline $50-64$ years & 178 & 0.126 & 0.018 & $7.2^{\star \star \star}$ & 181 & 0.069 & 0.013 & $5.5^{\star \star \star}$ \\
\hline All men & 550 & 0.114 & 0.009 & $12.5^{\star \star \star}$ & 558 & 0.077 & 0.007 & $11.6^{\star \star \star}$ \\
\hline \multicolumn{9}{|l|}{ Women } \\
\hline $19-24$ years & 43 & 0.038 & 0.021 & 1.8 & 44 & 0.040 & 0.018 & $2.2^{*}$ \\
\hline $25-34$ years & 144 & 0.075 & 0.017 & $4.4^{\star \star \star}$ & 145 & 0.045 & 0.014 & $3.3^{\star \star}$ \\
\hline $35-49$ years & 269 & 0.131 & 0.017 & $7.8^{\star * *}$ & 277 & 0.060 & 0.011 & $5.4^{\star \star \star}$ \\
\hline $50-64$ years & 195 & 0.170 & 0.020 & $8.6^{\star \star *}$ & 199 & 0.105 & 0.015 & $7.0^{\star \star \star}$ \\
\hline All women & 660 & 0.112 & 0.010 & $11.6^{* * *}$ & 674 & 0.065 & 0.007 & $9.3^{\star \star *}$ \\
\hline All subjects & 1212 & 0.113 & 0.007 & $16.9^{\star \star \star}$ & 1234 & 0.071 & 0.005 & $14.3^{\star \star \star *}$ \\
\hline
\end{tabular}

SE - standard error.

For each of these calculations, $\log _{\mathrm{e}}($ blood $\mathrm{Hg}$ ) was the dependent variable and the selenium index was an independent variable, adjusted for age. In all cases the relationship was positive (i.e. direct).

${ }^{\star \star *} P<0.0001,{ }^{* \star} P=0.01-0.0001,{ }^{*} P=0.05-0.01$; otherwise not significant $(P>0.05)$ 
Table 4 Linear regression of square-root-transformed food group intakes versus $\log _{\mathrm{e}}(\mathrm{blood} \mathrm{Hg})$, $\log _{e}\left(\right.$ red-cell Se) and $\log _{e}($ plasma Se) concentrations

\begin{tabular}{|c|c|c|c|c|c|c|}
\hline \multirow[b]{2}{*}{ Food group } & \multicolumn{2}{|c|}{$\begin{array}{l}\text { Regression vs. } \\
\log _{\mathrm{e}} \text { (blood Hg) }\end{array}$} & \multicolumn{2}{|c|}{$\begin{array}{l}\text { Regression vs. } \\
\log _{\mathrm{e}}(\text { red-cell Se) }\end{array}$} & \multicolumn{2}{|c|}{$\begin{array}{l}\text { Regression vs. } \\
\log _{\mathrm{e}} \text { (plasma Se) }\end{array}$} \\
\hline & $t$ & $P$ & $t$ & $P$ & $t$ & $P$ \\
\hline \multicolumn{7}{|l|}{ Direct correlations - fish } \\
\hline Fried white fish & 1.4 & 0.15 & -2.2 & 0.03 & -1.7 & 0.10 \\
\hline Other white fish & +8.2 & $<0.0001$ & +6.1 & $<0.0001$ & +5.7 & $<0.0001$ \\
\hline Shellfish & +8.9 & $<0.0001$ & +5.8 & $<0.0001$ & +5.1 & $<0.0001$ \\
\hline Oily fish & +19.2 & $<0.0001$ & +12.1 & $<0.0001$ & +11.4 & $<0.0001$ \\
\hline All fish & +19.7 & $<0.0001$ & +9.8 & $<0.0001$ & +9.6 & $<0.0001$ \\
\hline \multicolumn{7}{|l|}{ Direct correlations - non-fish } \\
\hline Rice & +6.1 & $<0.0001$ & +6.7 & $<0.0001$ & +4.4 & $<0.0001$ \\
\hline Other bread & +5.1 & $<0.0001$ & +3.1 & 0.002 & +2.4 & 0.02 \\
\hline Chicken and turkey dishes & +6.5 & $<0.0001$ & +2.4 & 0.01 & +3.5 & 0.0004 \\
\hline Salad & +9.6 & $<0.0001$ & +8.0 & $<0.0001$ & +7.0 & $<0.0001$ \\
\hline Raw tomatoes & +6.3 & $<0.0001$ & +6.5 & $<0.0001$ & +5.6 & $<0.0001$ \\
\hline Leafy green vegetables & +5.1 & $<0.0001$ & +3.8 & 0.0001 & +4.1 & $<0.0001$ \\
\hline Other vegetables & +7.4 & $<0.0001$ & +8.7 & $<0.0001$ & +6.7 & $<0.0001$ \\
\hline Apples and pears & +5.1 & $<0.0001$ & +4.4 & $<0.0001$ & 4.7 & $<0.0001$ \\
\hline Bananas & +5.2 & $<0.0001$ & +4.0 & $<0.0001$ & +4.2 & $<0.0001$ \\
\hline Other fruit & +8.4 & $<0.0001$ & +9.8 & $<0.0001$ & +8.0 & $<0.0001$ \\
\hline Wine & +8.8 & $<0.0001$ & +7.4 & $<0.0001$ & +6.5 & $<0.0001$ \\
\hline \multicolumn{7}{|l|}{ Inverse correlations } \\
\hline White bread & -5.3 & $<0.0001$ & -4.9 & $<0.0001$ & -3.5 & 0.0004 \\
\hline Whole milk & -6.1 & $<0.0001$ & -5.1 & $<0.0001$ & -4.0 & $<0.0001$ \\
\hline Potato chips & -5.4 & $<0.0001$ & -6.3 & $<0.0001$ & -5.5 & $<0.0001$ \\
\hline Sugar & -6.0 & $<0.0001$ & -7.0 & $<0.0001$ & -7.7 & $<0.0001$ \\
\hline
\end{tabular}

Except for fried white fish, the table records only those relatively strong relationships for which the correlation with the mercury index was significant at $t= \pm 5.0$ or better. The other food groups, which did not meet this criterion, are listed in full in the survey report. These included 11 categories of bread, cakes, sweet puddings and cereal products; nine of dairy products; 12 of butter and different types of fat spreads; two of eggs and egg dishes; 10 of meat products; 14 of fruit and vegetables; four of snacks and confectionery; and 10 of alcoholic and non-alcoholic beverages.

The regressions are adjusted for age and gender, and there were 1212 degrees of freedom.

significantly correlated with the intake of non-fried white fish: either directly $(+)$ for salad, leafy green vegetables, other vegetables, fruit juice and wine; or inversely $(-)$ for whole milk, meat pies and potato chips.

As noted above, for both the men and the women in the survey, blood mercury and plasma selenium concentrations increased significantly with increasing age. An ancillary question, therefore, is whether these increases might be at least partly attributable to increasing fish intakes with age. For the women, the highly significant direct linear correlation between age and $\log _{\mathrm{e}}($ blood $\mathrm{Hg}$ ), $t=+4.81$, $\mathrm{df}=684, P<0.0001$ became non-significant $(t=+1.6$, $P=0.12$ ) when adjusted for sqrt(total fish intake). For the men, the highly significant direct linear correlation between age and $\log _{\mathrm{e}}($ blood $\mathrm{Hg}$ ), $t=+5.37$, df $=564$, $P<0.0001$ became much less significant $(t=+3.05$, $P=0.002$ ) when adjusted for sqrt(total fish intake).

Of the two selenium status indices, plasma Se was more strongly correlated (directly) with age than was red-cell Se. For men and women respectively, the $t$-values for $\log _{\mathrm{e}}{ }^{-}$ transformed plasma Se versus age were 4.29 and 4.86 (both $P<0.0001)$, and these fell to 2.55 and $3.27(P=0.01$ and 0.001) when adjusted for sqrt(total fish intake). Therefore, although the fish adjustment effect here was considerable, it was less than in the case of mercury.

We also ascertained that whole-blood glutathione peroxidase activity, which was measured during the survey $^{16}$, was moderately strongly correlated with both plasma and red-cell selenium concentrations ( $t$-values of 6.3-7.0 for all subjects), whereas its correlation with the blood mercury index was much weaker $(t=+3.5)$. If $\log _{\mathrm{e}}\left(\right.$ blood $\mathrm{Hg}$ ) was introduced into the regression of $\log _{\mathrm{e}}{ }^{-}$ transformed plasma or red-cell Se (dependent variable) versus blood glutathione peroxidase (independent), then the partial regression attributable to $\log _{\mathrm{e}}($ blood $\mathrm{Hg}$ ) was marginally positive $(t=0.5-0.7)$ but was not significant, and was not inverse. Thus the mercury burden, at the levels seen in this survey, did not significantly affect the relationship between selenium status (i.e. its blood levels) and blood glutathione peroxidase activity.

\section{Discussion}

Since the median blood $\mathrm{Hg}$ concentration in UK adults was only about $5 \mathrm{nmoll}^{-1}$ whereas the median blood Se concentration was about $1300 \mathrm{nmoll}^{-1}$, the blood $\mathrm{Hg}$ concentration was at least two orders of magnitude lower than the blood Se concentration. No individuals had an $\mathrm{Hg} / \mathrm{Se}$ ratio approaching 1:1. This conclusion seems to be consistent with our observation that blood glutathione peroxidase activity was unaffected by variations in the mercury burden (because any major effect of mercury should have created an inverse relationship whereby high mercury levels would have diminished the peroxidase 
activity for any given selenium level, and this was not observed).

Fish clearly provides one of the richer sources of selenium in the human diet ${ }^{1,21,22}$, although dietary sources of selenium are considerably more diverse than those of mercury, and include cereals and meat. Whereas many studies have found a correlation between fish consumption and selenium status, some have not ${ }^{23-25}$.

The data in Tables 1 and 2 of the present study are compatible with the prediction that dietary fish makes a major contribution to the intake of both mercury and selenium by British adults, and that the variation between individuals in their intakes and status of these two elements is highly sensitive to differences in fish intake. Regular inclusion of fish in the diet is a characteristic that varies considerably between different individuals and between households. However, not all types of fish were equally predictive of the mercury and selenium indices in this survey. Whereas the intake of oily fish was strongly correlated with all three biochemical indices, the intake of fried white fish was not significantly correlated with any of them. Intakes of 'other' (non-fried) white fish and of shellfish were intermediate in terms of $t$-values for the correlations, but these two fish categories contained far fewer non-zero intake values than the other two, which is partly responsible for their lower $t$-values. Therefore the question arises whether fried white fish differs substantially from oily fish and the other two fish categories in its content of mercury and selenium. Although some of the oily fish that is consumed, such as fresh tuna, is near the top of the marine food chain and has relatively high mercury content, other oily fish such as mackerel, herring and sardines are lower in the food chain and should therefore be less contaminated ${ }^{22}$. The selenium content of oily fish such as herring and mackerel appears to be similar to that of fish used for fried white fish dishes such as cod, haddock and plaice, although shellfish are reported to have a higher selenium content ${ }^{22}$. Table 3 confirms the prediction that the mercury and selenium indices are strongly correlated with each other, within the blood of nearly all the age-gender subgroups in the survey and in all subjects combined. A common dietary source of both elements, which is encountered in fish, offers a partial explanation of the correlation of the biochemical indices. In addition to this explanation, selenium can also interact chemically with mercury to form specific complexes that may alter the tissue distribution and chemical properties of both of these elements, which probably helps to reduce the toxicity of mercury. An example of such an interaction known to occur in the bloodstream involves selenoprotein $\mathrm{P}$ in plasma, each molecule of which can bind large numbers of complexes that in turn each comprise one atom of Se and one of inorganic $\mathrm{Hg}$. Up to 1000 such units may be bound per molecule of selenoprotein $\mathrm{P}^{26,27}$. Whether there are analogous mercury-selenium complexes that involve methylmercury and occur within red blood cells is less clear. Nevertheless, several studies have recorded a strong direct relationship between blood (including redcell) mercury and selenium indices in circumstances where methylmercury from dietary fish is likely to be the major source of mercury exposure ${ }^{28-32}$. In human kidney samples with a high mercury content, selenium and mercury concentrations were correlated in approximately 1:1 molar ratio, whereas no correlation between the two elements was observed at lower mercury concentrations ${ }^{33}$, suggesting that extra selenium may be transferred into the kidney when it is needed so as to form a $1: 1 \mathrm{Hg}-\mathrm{Se}$ complex. In a number of animal and cell culture model systems, some protection against the damaging effects of methylmercury by selenium compounds has been reported $^{34-43}$, although the mechanisms and efficacy of selenium as an antidote remains controversial. Selenium may increase mercury accumulation in the brain, even though it can counteract the neurotoxicity of mercury ${ }^{44}$.

The relationships of food groups other than fish to the blood indices of mercury and selenium in the survey are examined in Table 4. The intake of these other food groups was not as strongly correlated as fish, especially oily fish. Some of the non-fish food groups listed in Table 4 are likely to be important dietary sources of selenium, such as chicken and turkey, bread and cereals, but few of them are considered to be significant sources of mercury. Some of the food groups that were directly correlated with the biochemical indices, such as wine and green vegetables, may be consumed regularly as part of meals that include fish, and this suggestion appears to be supported by the observation that these food groups were also correlated with non-fried white fish intakes. One possible explanation might be that whereas a 7-day diet estimate is too short to capture long-term fish use and its contribution to blood mercury with perfect accuracy, certain other food groups which tend to be eaten by those same people who have high intakes of non-fried white fish can also contribute to the prediction of blood mercury, although less strongly than fish intake per se. If true, then a longer period of dietary estimation should increase the partial correlation of mercury with fish intake and diminish the relative contribution of the other (related) food items; however, this has yet to be tested. Blood mercury concentrations increased markedly with age over the age range (19-64 years) of the survey. Our observation that the significance of this age trend was reduced drastically by the inclusion of sqrt(fish intake) in the model appears to be compatible with the hypothesis that much of the increasing age trend in blood mercury may be the result of a parallel increasing age trend in fish intake, and hence an increasing age trend in the intake of methylmercury from fish. Indeed, if the survey estimates of fish intake had been more precisely reflective of the long-term fish intakes of each survey respondent, then the adjustment effect might have been greater still and could perhaps have accounted 
for all of the observed age trend in blood mercury. For plasma selenium, the result of inclusion of sqrt(fish intake) had a less dramatic, but nevertheless important, effect on the observed age trend; therefore it seems reasonable to suggest that part, but not all, of the increasing age trend in plasma selenium may be due to an increasing intake of selenium from fish with increasing age.

The published survey reports ${ }^{13,16,17}$ have recorded the fact that those respondents who were receiving certain (income support) state benefits had significantly lower intakes of oily fish and shellfish, and significantly lower status index values for mercury and selenium, than people not receiving these state benefits. Our study has extended this finding by showing that there were highly significant social class differences in both fish intakes and mercury/ selenium indices, with the lower intakes and index values being associated with the more manual and less skilled social class categories.

In 1972, a Joint Food and Agriculture Organization of the United Nations/World Health Organization Expert Committee on Food Additives and Contaminants (JECFA) defined a provisional tolerable weekly intake (PTWI) of mercury as $0.3 \mathrm{mg}$ total $\mathrm{Hg}_{\text {week }}{ }^{-1}$ for adults, of which not more than $0.2 \mathrm{mg}$ should be methylmercury ${ }^{45}$. This is equivalent to 5 and $3.3 \mu \mathrm{g}$ (kg body weight) ${ }^{-1}$ week $^{-1}$ for a $60-\mathrm{kg}$ subject. The $3.3 \mu \mathrm{g} \mathrm{kg}^{-1}$ value for methylmercury was again upheld in 1989 and 2000; however, in 2003, an upper limit of $1.6 \mu \mathrm{g} \mathrm{kg}^{-1}$ week $^{-1}$ was recommended ${ }^{46}$ to ensure that the developing foetus, pregnant women and those about to become pregnant would be adequately protected. The US Environmental Protection Agency (EPA) established a reference dose for methylmercury which is only about one-fifth of the 1972 JECFA PTWI, namely $0.1 \mu \mathrm{g}$ (kg body weight ${ }^{-1}$ day $^{-1}\left(0.7 \mu \mathrm{g}^{-1} \mathrm{~kg}^{-1}\right.$ week $\left.^{-1}\right)$, and this was upheld in 2000 by the National Research Council $^{47}$. The 2003 JECFA PTWI and the EPA references doses correspond to blood $\mathrm{Hg}$ levels of 80 and $35 \mathrm{nmoll}^{-1}$, respectively. Guidelines from UK Health and Safety Executive ${ }^{20}$ considered blood $\mathrm{Hg}$ levels $>50 \mu \mathrm{g} \mathrm{l}^{-1}$ $\left(250 \mathrm{nmoll}^{-1}\right)$ to warrant medical intervention, and concluded that blood $\mathrm{Hg}$ in non-occupationally exposed individuals should normally fall below $3 \mu \mathrm{gl}^{-1}$ $\left(15 \mathrm{nmoll}^{-1}\right)$. However, it is clearly desirable that mercury intakes should be minimised. It is claimed that sea-fish are generally less contaminated with mercury than freshwater fish, e.g. in countries such as those of Scandinavia ${ }^{29}$. Pregnant women and women about to become pregnant are especially at risk, and are currently advised by the British Food Standards Agency to avoid eating certain large, long-lived predatory fish that are at the top of the food chain, including shark, marlin and swordfish, because these species contain relatively high mercury concentrations $^{48}$.

It may be possible to reduce mercury levels in fish still further, e.g. by fish-farming in a clean environment; this appears to be an important public health objective in view of the many known health benefits of fish consumption, and especially those of oily fish.

\section{Conclusions}

In a national survey of British adults no toxic levels of mercury were found, which is reassuring because of the known health benefits of fish, especially oily fish. Total fish intake was strongly correlated with blood indices of mercury and selenium, as was the intake of three subgroups of fish; the strongest correlation being with oily fish. In contrast, fried white fish intake was not significantly related to the blood indices of selenium and mercury status. A chemical interaction between selenium and mercury may further enhance the relationship between these two elements within the human body. There was indirect evidence to suggest that the increase of blood mercury with age may be largely attributable to an increase of fish intake with age. Public health advice to increase dietary fish intakes, especially oily fish, would be made less ambiguous if the mercury content of fish could be reduced. Our conclusion that both selenium and mercury blood indices were strongly dependent on the amount of oily fish intake by British adults suggests that the amount of oily fish intake is especially important in determining our exposure to both of these elements. It therefore appears prudent to (1) select those oily fish that have the most desirable (i.e. lowest) $\mathrm{Hg} / \mathrm{Se}$ ratio and (2) to pursue policies that are aimed at lowering the $\mathrm{Hg} / \mathrm{Se}$ ratio in oily fish stocks.

\section{Acknowledgements}

The survey was commissioned jointly by the Department of Health and the Food Standards Agency. It was carried out by the Social Survey Division of the Office for National Statistics, in conjunction with the Micronutrient Status Laboratory of MRC Human Nutrition Research. C Sieniawska, R Mensikov and A Clewlow carried out the ICP-MS analyses of $\mathrm{Hg}$ and Se at the University of Southampton, supervised by Dr HT Delves. We are grateful to the late Jan Gregory (Office for National Statistics) for her assistance with survey procedures and information, to the Food Standards Agency and University of Essex Archive for access to the survey data, and to Dr Margaret Rayman (University of Surrey) for advice during preparation of the manuscript.

\section{References}

1 Combs G. Selenium in global food systems. British Journal of Nutrition 2001; 85: 517-47.

2 Rayman M. The importance of selenium to human health. Lancet 2000; 356: 233-41.

3 Clarkson T, Hursh J, Sager P, Syversen T. Mercury. In: Clarkson T, Friber L, Nordberg G, Sager P, eds. Biological Monitoring of Toxic Metals. New York: Plenum Press, 1988; 199-246. 
4 Clarkson T. The three modern faces of mercury. Environmental Health Perspectives 2002; 110: 11-23.

5 Cabanero AI, Carvalho C, Madrid Y, Batoreu C, Camara C. Quantification and speciation of mercury and selenium in fish samples of high consumption in Spain and Portugal. Biological Trace Element Research 2005; 103: 17-35.

6 Scientific Advisory Committee on Nutrition, Committee on Toxicity of Chemicals in Food, Consumer Products and the Environment. Advice on Fish Consumption: Benefits and Risks. London: The Stationery Office, 2004. Also available at http://www.sacn.gov.uk/reports.

7 Ministry of Agriculture, Fisheries and Food. 1997 Total Diet Study: Aluminium, arsenic, cadmium, chromium, copper, lead, mercury, nickel, selenium, tin, zinc. Food Surveillance Information Sheet No. 191 [online], 1999. Available at http://archive.food.gov.uk/maff/archive/food/ infsheet/1999/no191/191tds.htm. Accessed 8 October 2006.

8 Harris H, Pickering I, George G. The chemical form of mercury in fish. Science 2003; 301: 1203.

9 Thomson CD, Robinson MF, Butler JA, Whanger PD. Longterm supplementation with selenate and selenomethionine: selenium and glutathione peroxidase (EC 1.11.1.9) in blood components of New Zealand women. British Journal of Nutrition 1993; 69: 577-88.

10 Cuvin-Aralar M, Furness R. Mercury and selenium interaction: a review. Ecotoxicology and Environmental Safety 1991; 21: 348-64.

11 Whanger P. Selenium in the treatment of heavy metal poisoning and chemical carcinogenesis. Journal of Trace Elements and Electrolytes in Health and Disease 1992; 6: 209-21.

12 Watanabe C. Modification of mercury toxicity by selenium: practical importance? Tohoku Journal of Experimental Medicine 2002; 196: 71-7.

13 Henderson L, Gregory J, Swan G. The National Diet and Nutrition Survey: Adults aged 19 to 64 years. Volume 1. Types and Quantities of Foods Consumed. London: The Stationery Office, 2002; 80.

14 Henderson L, Gregory J, Irving K, Swan G. The National Diet and Nutrition Survey: Adults aged 19 to 64 years. Volume 2. Energy, Protein, Carbohydrate, Fat and Alcohol Intake. London: The Stationery Office, 2003.

15 Henderson L, Irving K, Gregory J, Bates CJ, Prentice A, Birch M, et al. The National Diet and Nutrition Survey: Adults aged 19 to 64 years. Volume 3. Vitamin and Mineral Intake and Urinary Analyses. London: The Stationery Office, 2003.

16 Ruston D, Hoare S, Henderson L, Gregory J, Bates CJ, Prentice A, et al. The National Diet and Nutrition Survey: Adults aged 19 to 64 years. Volume 4: Nutritional Status (Anthropometry and Blood Analytes), Blood Pressure and Physical Activity. London: The Stationery Office, 2004.

17 Hoare J, Henderson L, Bates CJ, Prentice A, Birch M, Swan G, et al. The National Diet and Nutrition Survey: Adults aged 19 to 64 years. Summary Report. London: The Stationery Office, 2004; 130.

18 Sieniawska C, Mensikov R, Delves H. Determination of total selenium in serum, whole blood and erythrocytes by ICP-MS. Journal of Analytical Atomic Spectroscopy 1999; 14: 109-12.

19 Moreton J, Delves HT. Simple direct method for the determination of total mercury levels in blood and urine and nitric acid digest of fish by inductively-coupled plasma mass spectrometry. Journal of Analytical Atomic Spectrometry 1998; 13: 659-65.

20 UK Health and Safety Executive. Guidance, 6th ed. 1993

21 World Health Organization (WHO). Selenium. In: Environmental Health Criteria 58. Geneva: WHO, 1987; 1-306.

22 Ministry of Agriculture, Fisheries and Food. Survey of the concentrations of metals and other elements in marine fish and shellfish. Food Surveillance Information Sheet No. 151 [online], 1998. Available at http://archive.food.gov.uk/maff/ archive/food/infsheet/1998/no151/151fish.htm. Accessed 8 October 2006.

23 Bjornberg K, Vahter M, Petersson-Grawe K, Glynn A, Cnattingius S, Darnerud $\mathrm{P}$, et al. Methyl mercury and inorganic mercury in Swedish pregnant women and in cord blood: influence of fish consumption. Environmental Health Perspectives 2003; 111: 637-41.

24 Barany E, Bergdahl I, Bratteby L, Lundh T, Samuelson G, Skerfving $\mathrm{S}$, et al. Mercury and selenium in whole blood and serum in relation to fish consumption and amalgam fillings in adolescents. Journal of Trace Elements in Medicine and Biology 2003; 17: 165-70.

25 Lindberg A, Bjornberg K, Vahter M, Berglund M. Exposure to methylmercury in non-fish-eating people in Sweden. Environmental Research 2004; 96: 28-33.

26 Yoneda S, Suzuki KT. Detoxification of mercury by selenium by binding of equimolar $\mathrm{Hg}-\mathrm{Se}$ complex to a specific plasma protein. Toxicology and Applied Pharmacology 1997; 143: $274-80$

27 Yoneda S, Suzuki K. Equimolar $\mathrm{Hg}-\mathrm{Se}$ complex binds to selenoprotein P. Biochemical and Biophysical Research Communications 1997; 231: 7-11.

28 Hongo T, Watanabe C, Himeno S, Suzuki T. Relationship between erythrocyte mercury and selenium in erythrocyte, plasma and urine. Nutrition Research 1985; 5: 1285-9.

29 Svensson B-G, Schutz A, Nilsson A, Akesson I, Akesson B, Skerfving S. Fish as a source of exposure to mercury and selenium. Science of the Total Environment 1992; 126: $61-74$.

30 Luoma P, Nayha S, Pyy L, Korpela H, Hassi J. Blood mercury and serum selenium concentrations in reindeer herders in the arctic area of northern Finland. Archives of Toxicology. Supplement 1992; 15: 172-5.

31 Grandjean P, Nielsen G, Jorgensen P, Horder M. Reference intervals for trace elements in blood: significance of risk factors. Scandinavian Journal of Clinical and Laboratory Investigation 1992; 52: 321-37.

32 Grandjean P, Wiehe P, Needham L, Burse V, Patterson JD, Sampson E, et al. Relation of a seafood diet to mercury, selenium, arsenic, and polychlorinated biphenyl and other organochlorine concentrations in human milk. Environmental Research 1995; 71: 29-38.

33 Drasch G, Wanghoefer E, Roider G, Strobach S. Correlation of mercury and selenium in the human kidney. Journal of Trace Elements in Medicine and Biology 1996; 10: 251-4.

34 Ganther H, Goudie C, Sunde M, Kopecky M, Wagner P, Oh S-H, et al. Selenium: relation to decreased toxicity of methylmercury added to diets containing tuna. Science 1972; 175: $1122-4$.

35 Johnson S, Pond W. Inorganic vs organic Hg toxicity in growing rats: protection by dietary Se but not Ze. Nutritional Reports International 1974; 9: 135-47.

36 Potter S, Matrone G. Effect of selenite on the toxicity of of dietary methylmercury and mercuric chloride in rats. Journal of Nutrition 1974; 104: 638-47.

37 Stoeswand G, Bache C, Lisk D. Dietary selenium protection of methylmercury intoxication of Japanese quail. Bulletin of Environmental Contamination Toxicology 1974; 11: 152-6.

38 Iwata $\mathrm{H}$, Okamoto $\mathrm{H}$, Ohsawa $\mathrm{Y}$. Effect of selenium on methylmercury poisoning. Research Communications in Chemical Pathology and Pharmacology 1978; 5: 673-80.

39 Sumino K, Yamamoto R, Kitamura S. A role of selenium against methylmercury toxicity. Nature 1977; 268: 73.

40 Toshima N, Hiroshi S, Tsuguyoshi S. Effects of sodium selenite on methylmercury embryotoxicity and teratogenicity. Toxicology and Applied Pharmacology 1979; 47: 79-88.

41 Frederiksson A, Gardlund A, Bergman K, Oskarsson A, Ohlin B, Danielsson B, et al. Effects of maternal dietary supplementation with selenite on the postnatal develop- 
ment of rat offspring exposed to methylmercury in utero. Pharmacology and Toxicology 1993; 72: 377-82.

42 Park S, Lim K, Chung Y, Kim S. Methylmercury-induced neurotoxicity in cerebral neuron culture is blocked by antioxidants and NMDA receptor antagonists. Neurotoxicology 1996; 17: 37-45.

43 Frisk P, Yaqob A, Nilsson K, Lindh U. Selenite or selenomethionine interaction with methylmercury on uptake and toxicity showing a weak selenite protection: studies on cultured K-562 cells. Biological Trace Element Research 2001; 80: 251-68.

44 Whanger P. Selenium and the brain: a review. Nutrition in Neuroscience 2001; 4: 81-97.

45 World Health Organization (WHO). Evaluation of Mercury, Lead, Cadmium, and the Food Additives Amaranth, Diethylpyrocarbonate and Octyl Gallate. WHO Food Additives Series No. 4. Geneva: WHO, 1972 Also available at http://www.inchem.org/documents/jecfa/jecmono/v004je02.htm

46 Joint Food and Agriculture Organization of the United Nations/World Health Organization Expert Committee on Food Additives and Contaminants (JECFA). Safety evaluation of certain food additives and contaminants; methylmercury. In: Summary and Conclusions of the 61st JECFA meeting, Rome, 10-19 June 2003 [online], 2003. Available at http:// www.who.int/ipcs/food/jecfa/summaries/en/summary_61. pdf. Accessed 8 October 2006.

47 National Research Council. Toxicological Effects of Methylmercury. Washington, DC: National Academy Press, 2000.

48 Food Standards Agency. New guidance on eating shark, swordfish and marlin [online], 10 May 2002. Available at http://www.foodstandards.gov.uk/news/newsarchive/ 62565. Accessed 13 May 2002. 